\title{
Actividad con alumnos de Nivel básico I de EOI Ingenio (Gran Canaria) Curso 2013-14
}

\author{
José Luis Diez Naz \\ EOI Las Palmas de Gran Canaria II
}

http:// dx.doi.org/10.12795/mAG Azin.2016.i24.04

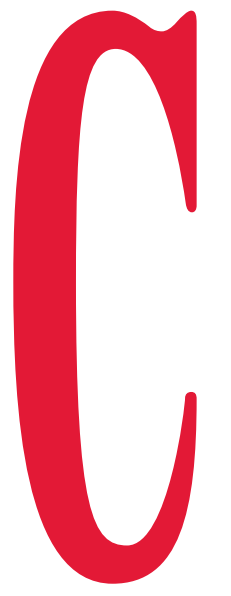

omo colofón de lo aprendido durante el curso se hizo a finales de abril una entrevista en alemán a germanoparlantes en Playa del Inglés que gustó mucho a los participantes, según testimonio posterior de los alumnos: habían aprendido a manejarse en alemán con hablantes nativos en tan sólo meses después de haber iniciado su aprendizaje.

Una vez vistas las grabaciones hechas por los mismos alumnos con sus móviles de las entrevistas, se seleccionaron aquellas que habían quedado mejor y se pusieron 2 de ellas en la página de la escuela. (se las puede visionar entrando en EOI INGENIO, ACTIVIDAD DE ALEMÁN).

\section{Actividad realizada en Playa del Inglés, Curso 2013-14}

El procedimiento de trabajo fue como sigue:

1. Primeramente se trabajó en clase las preguntas que se iban a formular. 5 debían ser comunes a todos los alumnos, que actuarían en pareja: uno formulando la pregunta y otro grabando (con el permiso del entrevistado) la entrevista. Otras 5 preguntas eran libres para cada pareja entrevistadora, habiendo sido corregidas por el profesor previamente.

2. Se ensayó también en clase los días previos a la actividad, haciendo entre ellos ambos roles (entrevistador o turista) para ponerse mejor en la piel de los futuros implicados y poder prever posibles fallas.

3. Quedamos en el Hotel Maritim de Playa del Inglés (sur de Gran Canaria) el jueves previo a vacaciones de Semana Santa por la tarde sobre las 17:00, yendo los alumnos en sus propios vehículos. Los menores de edad habían llevado a sus casas solicitud de permiso a los padres que hubieron de entregar previamente en clase al profesor para poder realizar la actividad.

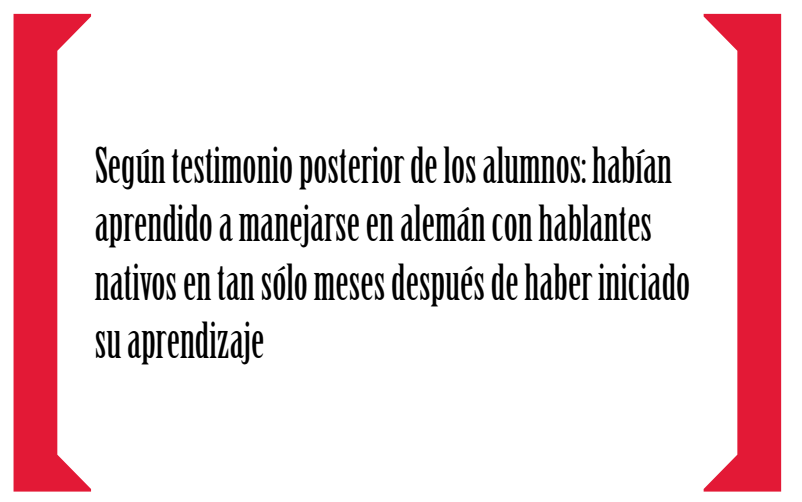

4. Una vez allí abajo todos los que se habían comprometido a participar (unas 10 personas) nos repartimos por el paseo marítimo, y quedamos en vernos una hora más tarde en la terraza de una heladería para refrescarnos y cambiar impresiones sobre lo sucedido.

Los alumnos tuvieron que pedir su comanda en alemán, para seguir con la comedia, aunque algunos habían trabajado incluso en alguno de los locales adyacentes y creían poder ser reconocidos por antiguos compañeros de trabajo o jefes. 


\section{MODELO DE ENCUESTA}

1. (ALUMN@) Entschuldigung, sprechen Sie Deutsch? (TOURIST) Ja.

2. (ALUMN@) Wir lernen Deutsch an einer Sprachschule. Als praktische Aufgabe möchten wir eine Umfrage machen. Können Sie uns helfen?

3. (TOURIST) Nein

(ALUMN@) Danke schön. Einen guten Aufenthalt auf Gran Canaria! (TOURIST) Ja.

(ALUMN@) Dürfen wir aufnehmen?

(TOURIST) Ja / Nein.

(ALUMN@) Die erste Frage ist:

* Wie ist Ihr Name?

* Wo sind Sie geboren?

*Woher kommen Sie?

* Was sind Sie von Beruf?

* Sprechen Sie Spanisch?

* (pregunta libre)

* (pregunta libre)

* (pregunta libre)

*(pregunta libre)

*(pregunta libre)

4. (ALUMN@) Vielen Dank für Ihre Mitarbeit. Einen guten Aufenthalt auf Gran Canaria! 